\title{
Mathematical modelling of the effect of fire exposure on a new type of protective clothing
}

\author{
G. N. Mercer ${ }^{1}$ H. S. Sidhu ${ }^{2}$
}

(Received 30 July 2007; revised 3 December 2007)

\begin{abstract}
We model the behaviour of heat transport through a new type of protective clothing that varies its properties with temperature. Heat absorption due to phase change within the material is used to limit the heat conduction of the material. We investigate the performance of such a material to determine the possibility of using these types of materials as protective clothing for firefighters. Clothing with embedded phase change material is found to give significantly more protection than conventional firefighting clothing.
\end{abstract}

\section{Contents}

1 Introduction

See http://anziamj.austms.org.au/ojs/index.php/ANZIAMJ/article/view/346 for this article, (c) Austral. Mathematical Soc. 2008. Published January 8, 2008. ISSN 1446-8735 


\section{Mathematical model}

3 Determining degree of skin burn

C294

4 Results

4.1 Flash fire scenario . . . . . . . . . . . . . . C295

4.2 Low intensity firefighting . . . . . . . . . . . C298

5 Conclusion

C301

References

C302

\section{Introduction}

Firefighting is generally considered to be a hazardous occupation and in order to minimize burn injuries appropriate thermal protective clothing must be worn. This protective clothing is chosen for its thermal and fire resistant properties. Other factors such as weight, bulk, ease of movement and moisture transport [3] are also important considerations. Here we investigate the effects of having a phase change material (PCM) embedded as a layer in firefighting clothing. The PCM is solid below a certain temperature and absorbs heat and changes from solid to liquid as the temperature rises. Of interest here is whether this heat absorption offers thermal protection to the firefighter. In particular, we are interested in whether this reduces the risk of skin burns to the firefighters when subject to both flash fires and more general lower intensity fire fighting scenarios.

The incorporation of PCM into textiles is not new but has primarily been used as a method of retaining heat $[8,13,16,17]$ for use in cold conditions. The PCM is enclosed in small polymer spheres of only a few micrometres in diameter and is often referred to as micropcm. Due to its small size this microPCM can be incorporated into material in relatively thin layers. This 
means that it can be used in firefighting clothing without greatly increasing the weight or bulk and maintaining the range of movement necessary for firefighting activities. These types of materials are currently not used for firefighting clothing hence the aim of this article is to demonstrate the worth of developing this technology further for this application.

Any PCM used should be solid at ambient conditions so that there is no need for cooling prior to use. This pre-cooling is an issue with other mechanisms for cooling firefighters that have been used in the past including cool water or ice filled cool vests [2]. The PCM being solid at ambient conditions ensures that the clothing is always ready for firefighting duties and is easier to store and transport. Hence the PCM must be chosen so that it has a melting temperature in a useful range that provides thermal protection (typically $50-90^{\circ} \mathrm{C}$ ) and with a large enough heat of fusion to absorb substantial energy and slow the conduction of heat through the protective clothing.

\section{Mathematical model}

There are two types of mathematical models for the heat transfer through clothing and skin: those that only consider heat transfer [8, 11, 12, 14], and those that consider heat and moisture transfer $[3,5]$. We consider a model with only heat transfer as the effect of the PCM is larger than moisture transfer effects so the added complexity of including moisture transfer is not warranted. Given this research is aimed at assessing the worth of including PCM into firefighting clothing this is a reasonable first step.

Due to the length scales of clothing and skin thickness (in the order of $1 \mathrm{~cm}$ ) compared to typical surfaces of 5 to $20 \mathrm{~cm}$ in length and/or breadth, a one dimensional model is a valid assumption. Hence we are only interested in the direction normal to the clothing and skin surface. The clothing is assumed to consist of three layers (a hard wearing flame resistant and waterproof outer shell, a middle microPCM layer and an inner thermal insulating liner). 


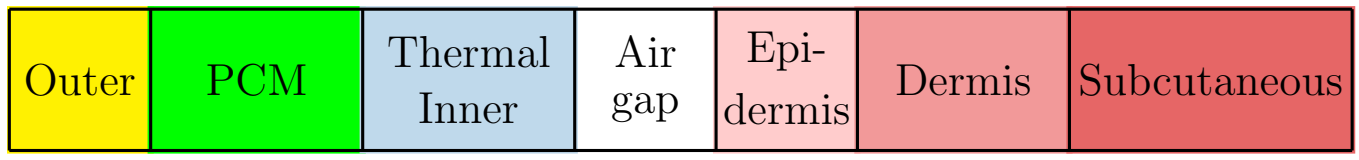

Clothing

Skin

FiguRE 1: Schematic diagram of the layers used in the model.

In keeping with other skin burn models $[11,14]$ the skin is also assumed to consist of three layers (the epidermis, dermis and subcutaneous layers). An air gap between the clothing and skin is also allowed for. The different layers are shown schematically in Figure 1.

The governing equation describes heat conduction through the layers. Also included are the latent heat of fusion in the PCM layer and blood perfusion in the dermis and subcutaneous layers (this removes heat from the skin region if it is above the core body temperature). Thus the governing equation is

$$
\rho C \frac{\partial T}{\partial t}=\frac{\partial}{\partial x}\left(k \frac{\partial T}{\partial x}\right)-G \rho_{b} C_{b}\left(T-T_{c}\right)+\rho Q \frac{\partial Z}{\partial t} .
$$

Here $\rho$ is the density $\left(\mathrm{kg} \mathrm{m}^{-3}\right), C$ the specific heat $\left(\mathrm{J} \mathrm{kg}^{-1} \mathrm{~K}^{-1}\right), T$ the temperature $(\mathrm{K}), t$ the time $(\mathrm{s}), k$ the thermal conductivity $\left(\mathrm{J} \mathrm{m}^{-1} \mathrm{~s}^{-1} \mathrm{~K}^{-1}\right), G$ the blood perfusion rate $\left(\mathrm{m}^{3} \mathrm{~s}^{-1} \mathrm{~m}^{-3}\right.$, volume of blood per second per volume of skin tissue, only applicable in the dermis and subcutaneous layers), $x$ is the spatial variable through the clothing and into the skin, $Q$ the heat of fusion $\left(\mathrm{J} \mathrm{kg}^{-1}\right)$ of the PCM, $Z$ is the solid fraction present in the PCM layer $(Z=1$ is solid, $Z=0$ is liquid) and the subscripts $b$ and $c$ refer to blood and core body temperature respectively. The thermal-physical properties are assumed constant within a layer but varying between layers. This is reasonable given the temperature range involved. Table 1 gives typical values and those used here $[3,14]$. The air gap used of $0.5 \mathrm{~mm}$ is at the lower end of the range typically used in testing which is from $6 \mathrm{~mm}$ to touching (no air gap) [15]. As 
TABLE 1: Thermal and physical parameters of the clothing, air and skin used in the model for the different layers as shown in Figure 1.

\begin{tabular}{lccccccc} 
Property & Outer & PCM & Inner & Air Gap & Epider. & Dermis & Subcut. \\
\hline$\rho\left(\mathrm{kg} / \mathrm{m}^{3}\right)$ & 286 & 2000 & 220 & 1.18 & 1200 & 1200 & 1000 \\
$C(\mathrm{~J} /[\mathrm{kg} \mathrm{K}])$ & 1005 & 110 & 1300 & 1005 & 3600 & 3300 & 2500 \\
$k(\mathrm{~J} /[\mathrm{s} \mathrm{m} \mathrm{K}])$ & 0.08 & 0.65 & 0.052 & 0.026 & 0.24 & 0.45 & 0.18 \\
Width $(\mathrm{mm})$ & 0.7 & 1.0 & 0.95 & 0.5 & 0.080 & 2.0 & 10.0 \\
$\mathrm{G}\left(\mathrm{m}^{3} /\left[\mathrm{s} \mathrm{m}^{3}\right]\right)$ & $\mathrm{n} / \mathrm{a}$ & $\mathrm{n} / \mathrm{a}$ & $\mathrm{n} / \mathrm{a}$ & $\mathrm{n} / \mathrm{a}$ & $\mathrm{n} / \mathrm{a}$ & 0.00125 & 0.00125
\end{tabular}

such the results presented here are on the pessimistic side which is warranted for safety considerations. As PCMs are not currently incorporated in firefighting clothing a PCM material was used that represented a material with the type of properties that would be beneficial in firefighting scenarios. Table 1 of Zalba et al. [18] provides substantial data on many different types of PCM available. Here we choose one with a melting temperature of $78^{\circ} \mathrm{C}$ over a range of $\pm 2^{\circ} \mathrm{C}$ and a heat of fusion of $267 \mathrm{~kJ} \mathrm{~kg}^{-1}$. This is in the acceptable range for melting temperature so that the temperature in the clothing will be stalled around this melting temperature until the majority of the PCM melts but also sufficiently high enough so that it can be guaranteed to be solid under normal non-firefighting wearing conditions and is easily stored in a ready state.

The initial condition within the skin is commonly taken to be a linear temperature profile from the inner core temperature of $37^{\circ} \mathrm{C}$ to the outer skin temperature of $34^{\circ} \mathrm{C}$. For simplicity the initial temperature of the clothing and air gap are also taken as $34^{\circ} \mathrm{C}$. The precise values taken for the initial temperatures do not have a large impact on the results presented here. The boundary condition at the base of the subcutaneous layer is that the temperature is maintained at the body's core temperature of $37^{\circ} \mathrm{C}$. The base of the subcutaneous region is far enough from the heat source that this is a reasonable assumption. Continuity in temperature is assumed throughout 
the clothing, air gap and skin layers. The outer boundary condition on the clothing surface depends on the scenario being modelled. A common boundary condition for both flash fire and more general firefighting scenarios is to assume a given heat flux onto the clothing. For intense flash fires this is taken to be $83.2 \mathrm{~kW} \mathrm{~m}^{-2}$ for a period of 3 seconds followed by a period of heat transfer to the ambient surroundings [14]. This is in keeping with bench top testing methods [1]. For lower intensity fire fighting scenarios the heat flux is taken to be $1.2 \mathrm{~kW} \mathrm{~m}^{-2}$ for periods of 5 minutes.

The melting of the PCM layer is allowed for by the $\rho Q \frac{\partial Z}{\partial t}$ term in equation (1). Latent heat is absorbed as the solid PCM melts and $Z$ changes from 1 to $0 . Z$ is represented by the smooth function

$$
Z=\frac{1}{2} \operatorname{erfc}\left(\frac{T-T_{m}}{T_{0}}\right)
$$

where $T_{m}$ is the melting temperature of the PCM and $T_{0}$ is the range over which the melting transition occurs (taken as $\pm 2^{\circ} \mathrm{C}$ here).

The governing equation (1) is solved with the appropriate initial and boundary conditions using a time and space adaptive finite element package FlexPDE ${ }^{\mathrm{TM}}[6]$. Due to its adaptive nature both space and time errors are minimized and more mesh points are used in regions of large gradients such as at the clothing surface. All calculations are performed to a relative error tolerance of less than $0.1 \%$.

\section{Determining degree of skin burn}

Damage to the skin commences when the temperature in the tissue rises above $44^{\circ} \mathrm{C}$ [14]. By considering the damage to the tissue as a first order Arrhenius kinetics chemical reaction, Henriques [9] devised a model for the thermal damage which has subsequently been used by numerous authors $[3$, 
$4,10,11,12]$. By defining $\Omega(t)$ as the cumulative time dependent damage function for temperatures above $44^{\circ} \mathrm{C}$, then according to first order kinetics

$$
\Omega(t)=\int_{0}^{t} P \exp \left(\frac{\Delta E}{R(T(\tau)+273)}\right) d \tau \quad \text { when } T(\tau)>44,
$$

with the accepted values for the pre-exponential being $P=3.1 \times 10^{98} \mathrm{~s}^{-1}$ and the ratio of the activation energy to the universal gas constant as $\Delta E / R=$ $75000 \mathrm{~K}[14] . \Omega(t)$ is a highly nonlinear function and the generally used definitions of burns in terms of $\Omega(t)$ are: first degree burn occurs at $\Omega(t)=0.53$; second degree burn at $\Omega(t)=1.0$; third degree burn at $\Omega(t)=10^{4}$ [12]. The medical definition of burn degree is less quantitative with first degree burns only involving the epidermis, second degree burns involving the epidermis and part of the dermis and third degree burns involving deeper tissue. We take the time to a first or second degree burn to be when the $\Omega(t)=0.53$ and 1.0 contours respectively reach the base of the epidermis. As the degree of burn encountered beneath protective clothing in firefighting scenarios is usually not severe we limit our attention to first and second degree burns.

\section{Results}

\subsection{Flash fire scenario}

The governing equations were solved for the flash fire scenario of a heat flux of $83.2 \mathrm{~kW} \mathrm{~m}^{-2}$ for 3 seconds for two cases and the burn integral equation (3) calculated throughout the skin layers. The first case (Figure 2) was with the PCM layer and the second case (Figure 3) has the PCM layer replaced by a thermal insulation layer with the same properties as the inner clothing layer which is typical of conventional firefighter clothing.

Figure 2 shows clearly the stalling in the temperature around the melting temperature of the $\mathrm{PCM}$ around $78^{\circ} \mathrm{C}$ with a resultant substantial lowering 


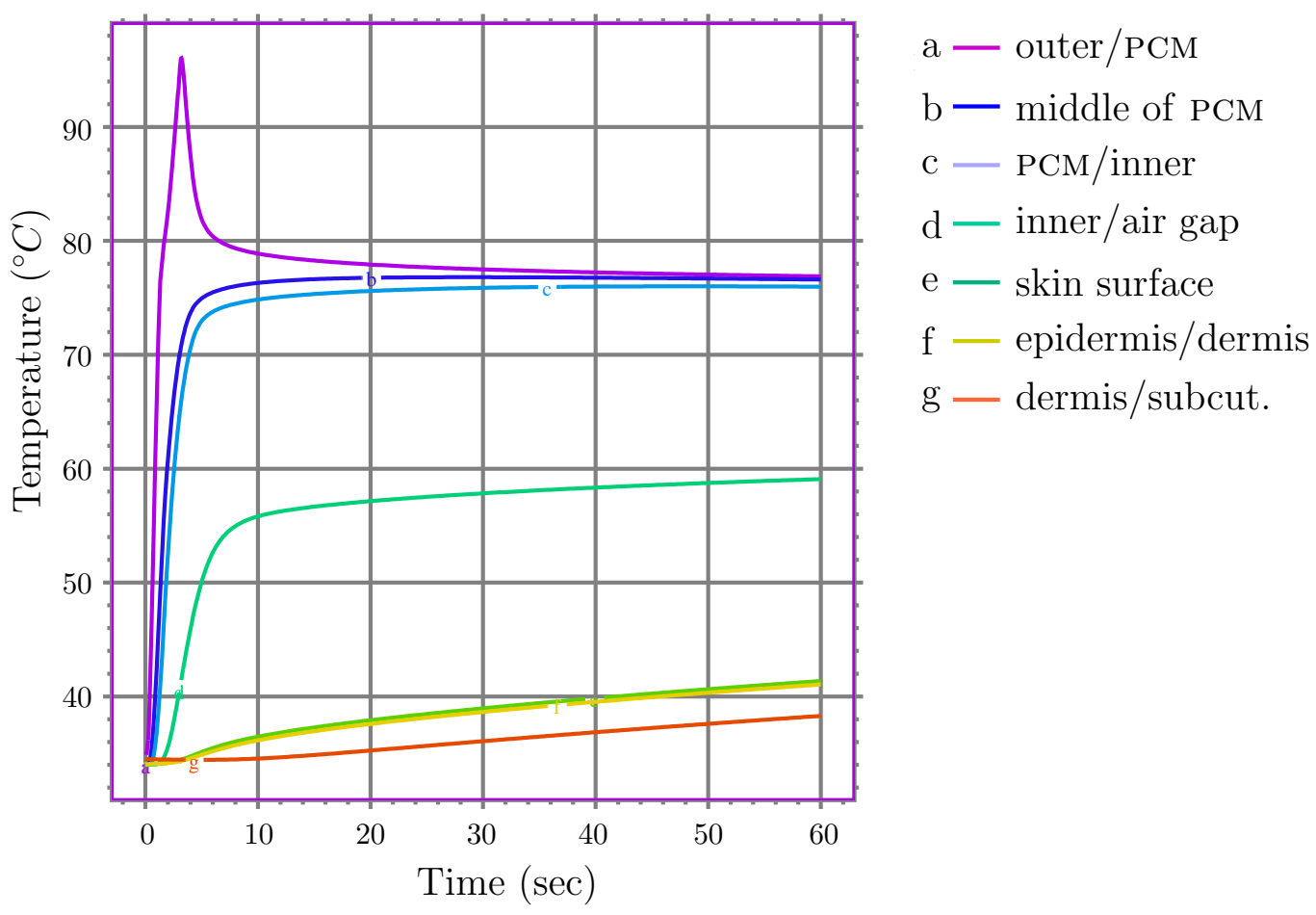

Figure 2: Temperature versus time at different layers in the clothing and skin when subjected to $83.2 \mathrm{~kW} \mathrm{~m}^{-2}$ for 3 seconds (flash fire) with a PCM layer present. 


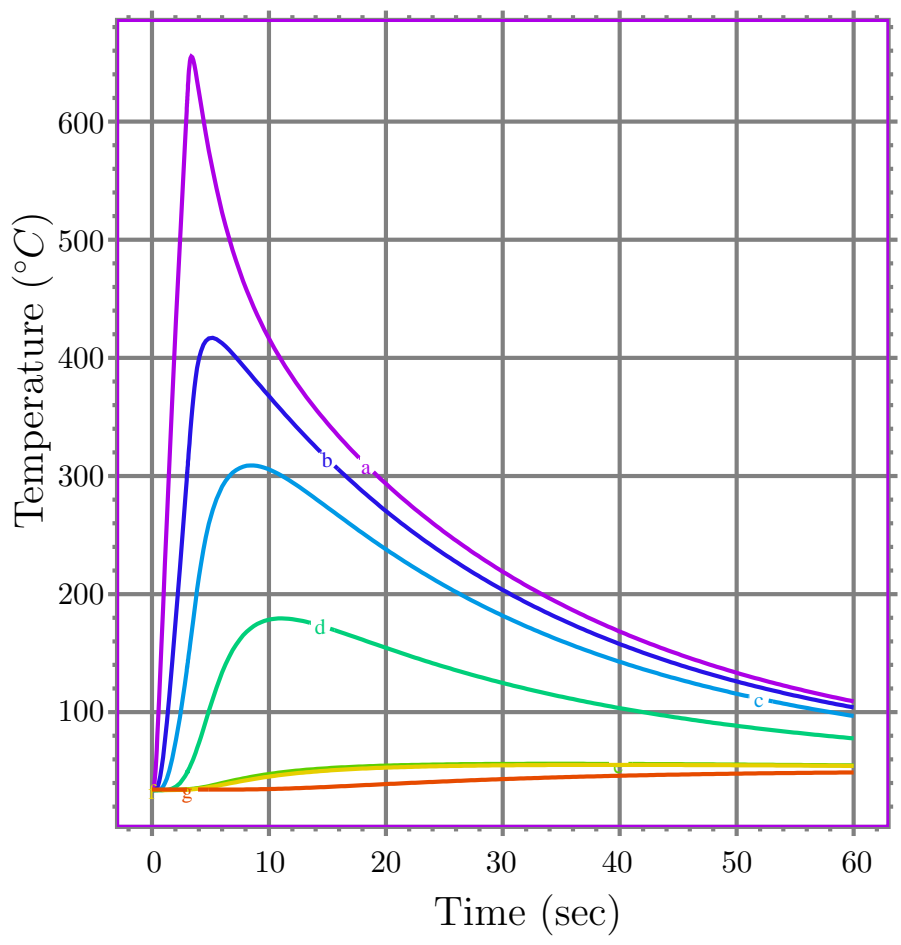

a - outer/PCM

$\mathrm{b}$ - middle of PCM

$\mathrm{c}$ - PCM/inner

$\mathrm{d}$ - inner/air gap

e - skin surface

$\mathrm{f}$ - epidermis/dermis

$\mathrm{g}$ - dermis/subcut.

Figure 3: Same temperature exposure as Figure 2 but with the PCM layer replaced by a thermal insulation material. 
of the temperature in the skin compared to Figure 3. The outer layer/PCM interface gets above the melting temperature (top curve) but the middle of the PCM layer (second to top curve) and the PCM/inner interface (3rd curve) peak at the melting temperature. Under this flash fire scenario the PCM has not fully melted and so provides a useful temperature buffer to the firefighter's skin. On calculating the time dependent cumulative burn integral over a time span of 300 seconds it is found that the PCM case results in no skin burn whereas the case with the PCM replaced by a thermal insulation layer results in a second degree burn to the base of the epidermis after approximately 29 seconds.

The PCM has provided substantial benefits in the flash fire scenario. However, there is still a question regarding its suitability for general lower intensity fire fighting operations that needs to be answered. Once the PCM layer has melted it has a poorer thermal performance than a purpose designed thermal insulation layer. Does the temperature buffering of the PCM compensate for this adequately and still provide reasonable long term protection?

\subsection{Low intensity firefighting}

To answer this question we take a lower heat flux onto the clothing of $1.2 \mathrm{~kW} \mathrm{~m}^{-2}$ for a period of 5 minutes to describe lower intensity fire fighting scenarios and calculate the temperature and burn integral within the skin. This level of heat flux is considered to be in the 'hazardous' category [7] for fire fighting and is one of the standard values used in testing [15]. The temperature time curves within the clothing and skin are shown in Figures 4 and 5 for the PCM layer and non-PCM layers respectively. Calculations were performed to a time of 10 minutes after the initial heat exposure.

Again the thermal arrest effect around $78^{\circ} \mathrm{C}$ is evident and has resulted in a lower temperature in the skin. Calculating the burn integral gives a second degree burn at the base of the epidermis at 440 seconds for the PCM case 


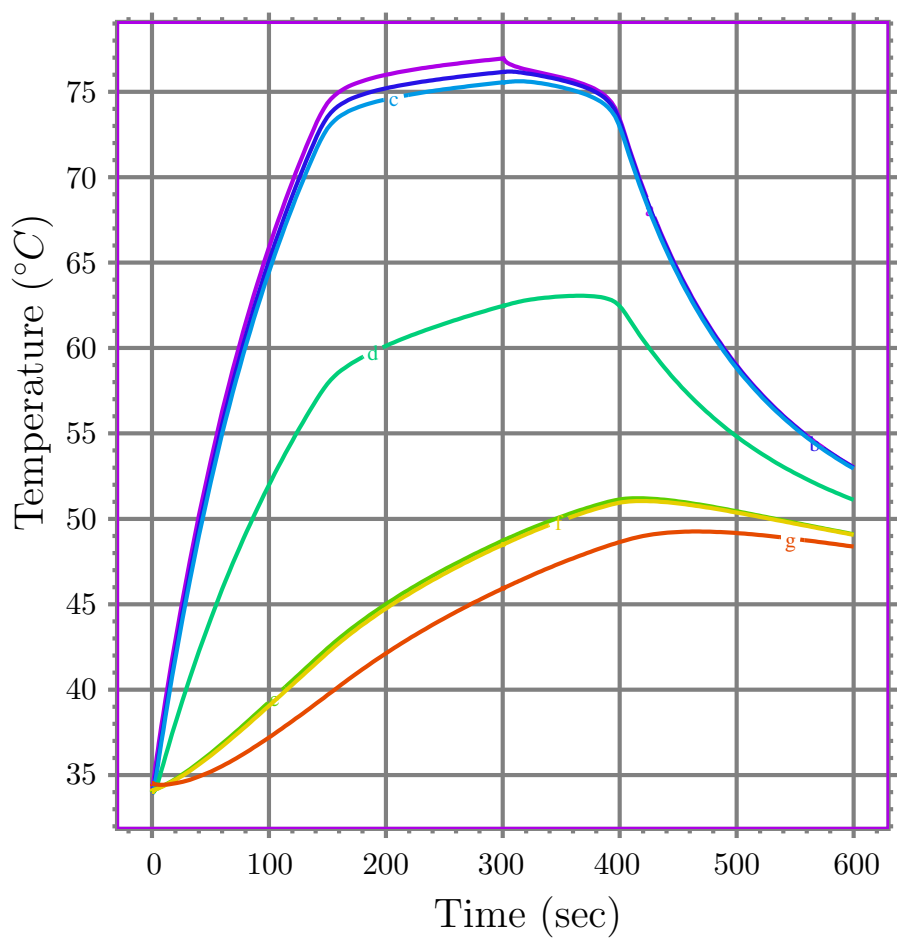

a - outer/PCM

$\mathrm{b}$ - middle of PCM

$\mathrm{c}$ - PCM/inner

$\mathrm{d}$ - inner/air gap

e - skin surface

$\mathrm{f}$ - epidermis/dermis

$\mathrm{g}$ - dermis/subcut.

Figure 4: Temperature versus time at different layers in the clothing and skin when subjected to $1.2 \mathrm{kWm}^{-2}$ for 300 seconds with a PCM layer present. 


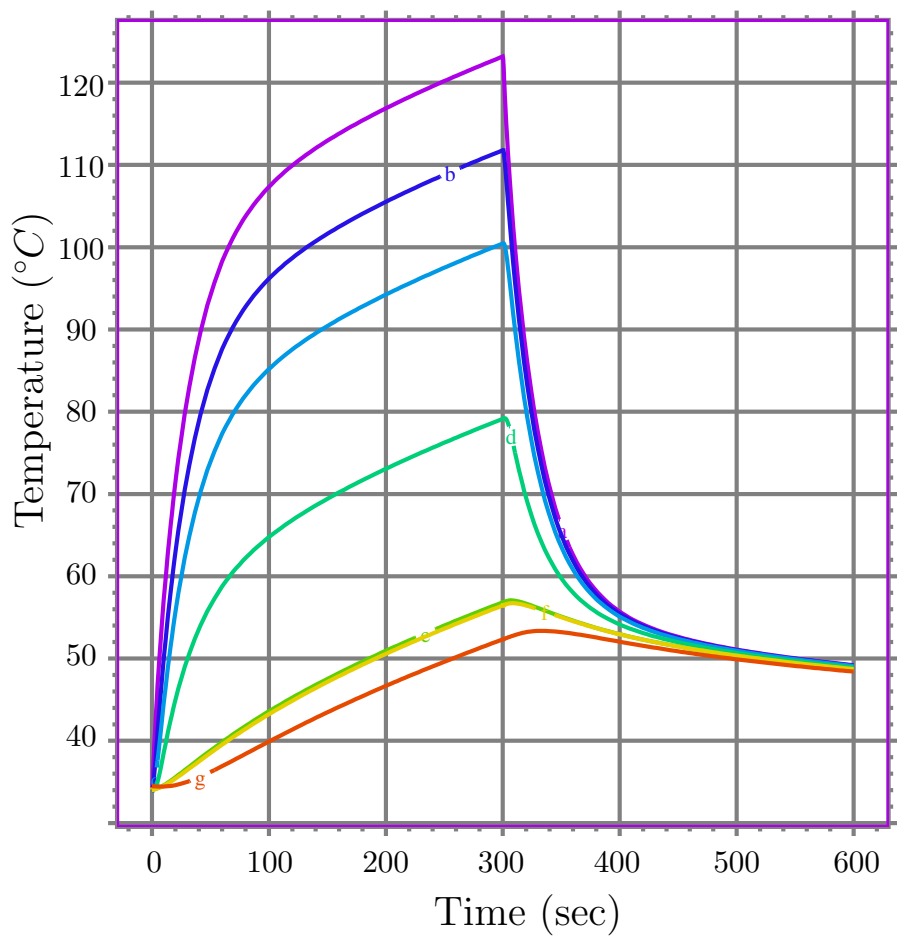

a - outer/PCM

$\mathrm{b}$ - middle of PCM

$\mathrm{c}$ - PCM/inner

$\mathrm{d}$ — inner/air gap

e - skin surface

$\mathrm{f}$ - epidermis/dermis

$\mathrm{g}$ - dermis/subcut.

Figure 5: Same temperature exposure as Figure 4 but with the PCM layer replaced by a thermal insulation material. 
compared to 240 seconds for the non-PCM case. Recall that these calculations were performed with a small air gap and hence are on the pessimistic side of predictions. So again there is considerable benefit from using the PCM embedded in the firefighting clothing. Once the heat flux is removed the temperature does not drop as quickly in the PCM case as resolidification of the PCM will release some heat but this is over a much longer time scale and does not adversely affect the chance of obtaining a skin burn.

\section{Conclusion}

We investigated the performance of a new type of protective clothing that varies its properties with temperature. We examined the performance of PCM embedded in firefighting clothing in two different fire scenarios: flash fire (intense heat flux for a short time interval) and low fire intensity (lower heat flux for a longer period of time). Our analysis has shown considerable protection for firefighters in both of these fire scenarios.

This preliminary work shows that there is scope for PCM to be embedded in firefighting clothing as a means of increasing the thermal protection afforded by the clothing. Substantial further work and testing is required but we believe it is a worthwhile endeavour given the results outlined in this research. Future work is needed on the design of these materials to determine the optimal phase change substrate to use, the optimal thickness of the PCM layer and its positioning within the material. As the PCM is denser than normal insulating material used in firefighting clothing, careful consideration of the weight of the clothing will also need to be taken into account so as to not make it too cumbersome. This will limit the thickness of the PCM layer able to be used. The $1 \mathrm{~mm}$ PCM layer used in the model here adds approximately $2 \mathrm{~kg}$ to the weight of a firefighters clothing which is quite acceptable given the increased protection it affords. 


\section{References}

[1] ASTMD 4108-87 standard test method for thermal protective performance of materials for clothing by open-flame method, 1987. American Society for Testing and Materials, West Conshohocken, PA. C294

[2] J. M. Carter, M. P. Rayson, D. M. Wilkinson, V. Richmod, and S. Blacker. Strategies to combat heat strain during and after firefighting. J. Thermal Biology, 32:109-116, 2007. doi:10.1016/j.jtherbio.2006.12.001. C291

[3] P. Chitrphiromsri and A. V. Kuznetsov. Modeling heat and moisture transport in firefighter protective clothing during flash fire exposure. Heat Mass Transfer, 41:206-215, 2005. doi:10.1007/s00231-004-0504-x. C290, C291, C292, C295

[4] K. R. Diller. Modeling thermal skin burns on a personal computer. Journal of Burn Care and Rehabilitation, 19:420-429, 1998. C295

[5] J. Fan and X. Y. Cheng. Heat and moisture transfer with sorption and phase change through clothing assemblies. Textile Research J., 75(3):187-196, 2005. doi:10.1177/004051750507500301. C291

[6] FlexPDE. http://www.pdesolutions. com. C294

[7] J. A. Foster and G. V. Roberts. Measurements of the firefighting environment - summary report. Fire Engineers J., 55:30-34, 1995. C298

[8] J. A. Gear, M. J. Lachut, and Y. Ding. Enhanced thermal performance of garments embedded with encapsulated phase change material. In Andrew Stacey, Bill Blyth, John Shepherd, and A. J. Roberts, editors, Proceedings of the 7th Biennial Engineering Mathematics and Applications Conference, EMAC-2005, volume 47 of 
ANZIAM J., pages C137-C151, July 2006.

http://anziamj . austms .org.au/V47EMAC2005/Gear. C290, C291

[9] F. C. Henriques. Studies of thermal injury V. The predictability and the significance of thermally induced rate processes leading to irreversible epidermal injury. Archives of Pathology, 43:489-502, 1947. C294

[10] S. C. Jiang, N. Ma, H. J. Li, and X. X. Zhang. Effects of thermal properties and geometrical dimensions on skin burn injuries. Burns, 28:713-717, 2002. doi:10.1016/S0305-4179(02)00104-3. C295

[11] G. N. Mercer and H. S. Sidhu. A heat transfer model describing burns to the skin from automotive airbags. In Andrew Stacey, Bill Blyth, John Shepherd, and A. J. Roberts, editors, Proceedings of the 7th Biennial Engineering Mathematics and Applications Conference, EMAC-2005, volume 47 of ANZIAM J., pages C339-C354, October 2006. http://anziamj . austms.org. au/V47EMAC2005/Mercer. C291, C292, C295

[12] E. Y. K. Ng and L. T. Chua. Comparison of one- and two-dimensional programmes for predicting the state of skin burns. Burns, 28:27-34, 2002. doi:10.1016/S0305-4179(01)00066-3. C291, C295

[13] H. Shim, E. A. McCullough, and B. W. Jones. Using phase change materials in clothing. Textile Research J., 6:4955 - 4962, 2001. C290

[14] D. A. Torvi and J. D. Dale. A finite element model of skin subjected to a flash fire. Journal of Biomechanical Engineering, 116:250-255, 1994. C291, C292, C294, C295

[15] R. L. Vettori, W. H. Twilley, and D.W. D. W. Stroup. Measurement techniques for low heat flux exposures to fire fighters protective clothing. 2001. National Institute of Standards and Technology, NISTIR 6750, Gaithersburg, MD. C292, C298 
[16] S. X. Wang, Y. Li, J. Y. Hu, H. Tokura, and Q. W. Song. Effect of phase-change material on energy consumption of intelligent thermal protective clothing. Polymer Testing, 25:580-587, 2006. doi:10.1016/j.polymertesting.2006.01.018. C290

[17] B. Ying, Y. Kwok, Y. Li, Q. Zhu, and C. Yeung. Assessing the performance of textiles incorporating phase change materials. Polymer Testing, 23:541-549, 2004. doi:10.1016/j.polymertesting.2003.11.002. C290

[18] B. Zalba, J. M. Marin, L. F. Cabeza, and H. Mehling H. Review on thermal energy storage with phase change: materials, heat transfer analysis and applications. Applied Thermal Eng., 23:251-283, 2003. doi:doi:10.1016/S1359-4311(02)00192-8. C293 


\section{Author addresses}

1. G. N. Mercer, School of Physical, Environmental and Mathematical Sciences, University of New South Wales at the Australian Defence Force Academy, Campbell, ACT 2600, Australia.

mailto:g.mercer@adfa.edu.au

2. H. S. Sidhu, School of Physical, Environmental and Mathematical Sciences, University of New South Wales at the Australian Defence Force Academy, Campbell, ACT 2600, Australia. 